\title{
A comparison of two different methods for formation of the beta phase in nanocomposites based on vinylidene fluoride-hexafluoropropylene copolymer
}

\author{
LyUdmila Borisova, Dimitrina KiRYakova*, Atanas ATANASSOV \\ Department of Materials Science, Assen Zlatarov University, Y. Yakimov Str. 1, Burgas 8010, Bulgaria
}

\begin{abstract}
Nanocomposite materials based on vinylidene fluoride-hexafluoropropylene copolymer and organically modified montmorillonite Cloisite ${ }^{\circledR} 15 \mathrm{~A}$ were prepared by two different methods: melt mixing and co-precipitation. The changes taking place in crystalline structure, tensile strength, thermal behavior and the formation of piezoelectric $\beta$-phase as a result of the polymer system dissolution in dimethyl sulfoxide were studied. The technological specificity of each method has certain effect on the properties of the obtained nanocomposites. The highest content of $\beta$-phase $-95 \%$ was achieved by co-precipitation from the solution of vinylidene fluoride-hexafluoropropylene copolymer in dimethyl sulfoxide and 6 mass $\%$ content of Cloisite ${ }^{\circledR} 15 \mathrm{~A}$. Despite the common view that the use of solvents and prolonged technological procedure lead to overall higher expenses, the obtained nanocomposites could be promising for the preparation of new piezo-materials.
\end{abstract}

Keywords: nanoclay; nanocomposites; vinylidene fluoride-hexafluoropropylene copolymer; $\beta$-phase

(C) Wroclaw University of Technology.

\section{Introduction}

There are four basic methods for synthesis of polymer/silicate materials: from melt, from solution, by in-situ polymerization and sol-gel techniques. Every polymer system requires selection of proper method and treatment conditions to obtain the desired product at highest efficiency. In the present paper, the experiments were limited to mixing from melt and mixing from solution so as to simplify the technological procedures, taking into account further implementation of the method directly in the industry.

In mixing from melt, a thermoplastic polymer is mixed with organophilized silicate above its temperature of glassification and melting, which results in intercalation of polymer chains between individual silicate layers [1]. The main disadvantage of this method is the slow penetration of the polymer melt in silicate channels.

The mixing from solution is based on a system where layered silicates swell in the solvent while polymer is dissolved. The layered silicate suspen-

*E-mail: dskiryakova@abv.bg sion and the polymer solution are mixed, hence, the polymer chains penetrate and substitute the solvent in the intermediate silicate layers. After removal of the solvent, a polymer nanocomposite is obtained [2]. Special attention should be paid to the proper selection of the solvent. It should be suitable for the polymer and the layered silicate and its organic modifier. There is a certain risk of solvent intercalation in the polymer, which is an unwanted process. Dimethyl sulfoxide (DMSO) is a common solvent for many polymers, suitable for the preparation of nanocomposites by co-precipitation method.

Vinylidene fluoride-hexafluoropropylene (VDF-HFP) copolymer with 15 mol \% HFP, similar to polyvinylidene fluoride (PVDF), crystallizes in at least four crystalline phases: $\alpha, \beta, \gamma$ and $\delta$. These modifications determine the unique properties and rich microstructure of PVDF and VDF copolymers. This polymorphism is related to the slightly bigger van der Waals radius of the fluorine atom $(1.35 \AA)$ compared to that of the hydrogen atom $(1.2 \AA)$ [3]. For the initial VDF-HFP copolymer, the non-polar $\alpha$-phase is dominating under crystallization from melt. The 
more polar $\beta$-phase is interesting from scientific point of view since it is responsible for the piezopyro- and photoelectric properties of the materials based on PVDF and the copolymers of VDF. Therefore, the efforts of researchers are focused on the preparation and increasing the content of the $\beta$-phase. This phase is directly connected with the trans-conformations of the polymer chains [4-6]. It is well known from the literature that the addition of montmorillonite fillers to polymers can stabilize a metastable phase and induce polymorphism. Typical examples are nanoclays stabilizing the $\beta$-phase in PVDF $[3,7,8]$.

The aim of the present work is to obtain nanocomposite materials on the basis of vinylidene fluoride-hexafluoropropylene copolymer with organically modified nanoclay Cloisite ${ }^{\circledR} 15 \mathrm{~A}$ by different methods and determine the tensile and other characteristics of the nanomaterials as well as the content of $\beta$-phase.

\section{Experimental}

\subsection{Materials}

Vinylidene fluoride-hexafluoropropylene copolymer referred to as VDF-HFP is a copolymer (15 mol \% HFP comonomer) with a melting temperature of $117{ }^{\circ} \mathrm{C}$ and a melt index of $6.52 \mathrm{~g} / 10$ $\min \left(220^{\circ} \mathrm{C}\right.$, load $\left.98 \mathrm{~N}\right)$ in the form of a powder, kindly supplied from Arkema, France. Organically modified montmorillonite nanoclay Cloisite ${ }^{\circledR} 15 \mathrm{~A}$, the product of Southern Clay Products Inc. was used. Cloisite ${ }^{\circledR} 15 \mathrm{~A}$ is $\mathrm{Na}^{+}$montmorillonite clay modified with dimethyl, dehydrogenated tallow, quaternary ammonium (2M2HT) with $d_{001}$ spacing of $31.5 \AA$ and density of $1.66 \mathrm{~g} / \mathrm{cm}^{3}$. HT stands for a tallow-based compound $(\sim 65 \% \mathrm{C} 18$, $\sim 30 \% \mathrm{C} 16, \sim 5 \% \mathrm{C} 14)$ in which the majority of the double bonds have been hydrogenated. The modifier concentration of Cloisite ${ }^{\circledR} 15 \mathrm{~A}$ was $125 \mathrm{meq} / 100 \mathrm{~g}$. The solvent used for the compositions was dimethyl sulfoxide (DMSO), Sigma Aldrich. All the materials described above were used directly without any further modification or treatment.

\subsection{Sample preparation}

\section{Melt mixing method}

The compositions containing $0.5,0.75,1.0,1.5$, 3.0 and 6.0 mass $\%$ of nanoclay Cloisite ${ }^{\circledR} 15 \mathrm{~A}$ were mixed with VDF-HFP copolymer and homogenized as a powder by stirring at $50-60{ }^{\circ} \mathrm{C}$ for $10 \mathrm{~min}$, and then twice in a laboratory twin-screw extruder at $200{ }^{\circ} \mathrm{C}$.

\section{Co-precipitation method}

The co-precipitation method was used to prepare VDF-HFP copolymer nanocomposites containing $0.5,0.75,1.0,1.5,3.0$ and 6.0 mass \% of nanoclay Cloisite ${ }^{\circledR} 15 \mathrm{~A}$. To obtain the nanoclay contents mentioned in the VDF-HFP copolymer, two premixes were made: one for the nanoclay and the other one for the VDF-HFP, using DMSO as a solvent. The two premixes were sonicated using a Branson 8510 ultrasonication bath at $30-40{ }^{\circ} \mathrm{C}$ for approximately $5 \mathrm{~min}$. The final $10 \%$ solution was prepared by adding the contents of the nanoclay premix to the VDF-HFP copolymer premix and the product was sonicated again for $20 \mathrm{~min}$. To the obtained mixture, $150 \mathrm{ml}$ of deionized water was added. A stringy, white, translucent precipitate was formed immediately. The precipitate was then removed and dried in a vacuum oven until it achieved a constant weight.

The samples obtained by co-precipitation method and these prepared by melt mixing were then pressed into films on a laboratory press PHI (England) between aluminum foils under the following conditions: sample thickness of $0.3-1 \mathrm{~mm}$, temperature $200{ }^{\circ} \mathrm{C}$, melting period at $200{ }^{\circ} \mathrm{C}-3$ min, pressing pressure $-12 \mathrm{MPa}$, cooling rate $40{ }^{\circ} \mathrm{C} / \mathrm{min}$.

\subsection{X-ray structure analysis}

The X-ray diffraction patterns were taken by $\mathrm{X}$-ray diffractometer with a generator Iris-

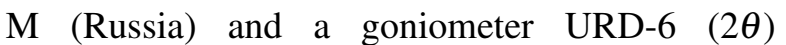
(Germany) under an atmospheric pressure at room temperature and Ni-filtered $\mathrm{Cu}$ target $\mathrm{K}_{\alpha}$ radiation in the interval $2 \theta=4-50^{\circ}$. 


\subsection{Fourier transform infrared spec- troscopy (FT-IR)}

Samples prepared as films were analyzed using spectrophotometer produced by "Bruker" (Germany) in the range of $4000-400 \mathrm{~cm}^{-1}$ with Tensor 27. To determine the relative quantity of the $\beta$-phase, the heights of the series of peaks were determined by simulation of the observed spectrum. This was done using OPUS-65 software which automatically corrected the baseline. For each sample, the fraction of the $\beta$-crystalline phase $\left(F_{\beta}^{I R}\right)$ was calculated by the formula: $F_{\beta}^{I R}=A_{\beta} /\left(1.26 A_{\alpha}+A_{\beta}\right)$, where: $A_{\alpha}$ and $A_{\beta}-$ are the heights of the peaks at 764 and $840 \mathrm{~cm}^{-1}$, respectively, and the coefficient 1.26 represents the ratio of the absorption coefficients at 764 and $840 \mathrm{~cm}^{-1}$ [9-11].

\subsection{Differential scanning calorimeter (DSC) measurements}

The behavior under melting and crystallization in nitrogen atmosphere of the samples with the mass of ca. $4 \mathrm{mg}$ was analyzed using simultaneous thermal analyzer "STA 449F3 Jupiter" (Netzsch, Germany) under the following conditions: first heating from 20 to $240{ }^{\circ} \mathrm{C}$ at a rate of $10{ }^{\circ} \mathrm{C} / \mathrm{min}$, isothermal period of $1 \mathrm{~min}$ at $240{ }^{\circ} \mathrm{C}$ (to remove any traces of crystalline structure) followed by cooling to $20^{\circ} \mathrm{C}$ and second heating to $240{ }^{\circ} \mathrm{C}$ at the same rate. The degree of crystallinity of the samples was calculated at $\Delta H_{100} \%=104.7 \mathrm{~J} / \mathrm{g}$ for $100 \%$ crystalline VDF-HFP copolymer [12].

\subsection{Tensile properties}

The tensile strength, elongation at break and other characteristics of the initial VDF-HFP copolymer and the nanocomposite materials based on it, were measured with a dynamometer INSTRON 4203 (England) at a speed of $100 \mathrm{~mm} / \mathrm{min}$ and room temperature.

\section{Results and discussion}

Organically modified montmorillonite nanoclays such as Cloisite ${ }^{\circledR} 15 \mathrm{~A}$, because of the rigid structure of clay layers and their high aspect ratio,

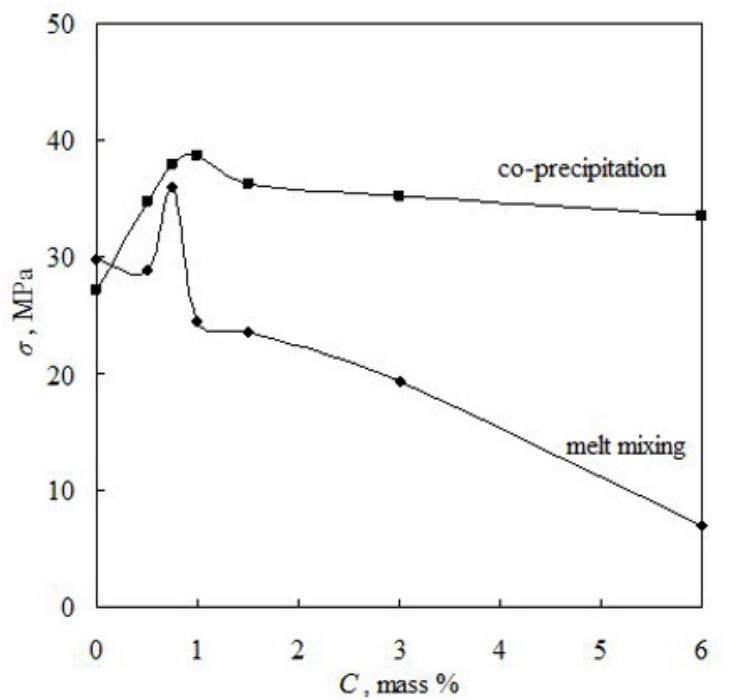

Fig. 1. Dependence of the tensile strength of the nanocomposite materials based on VDF-HFP copolymer on filler content.

are very effective fillers, which improve the mechanical properties of nanocomposites even at very low nanoclay additions in well dispersed condition. Therefore, the obtained nanocomposites were characterized by their tensile properties. The materials obtained by the co-precipitation method from a solution in DMSO showed more stable structure than those prepared from melt. They exhibited characteristics similar to those of the initial VDF-HFP copolymer and the materials obtained from melt. Thus, the values of tensile strength $\sigma$, remained in the range of 33.6 to $38.7 \mathrm{MPa}$, for different degrees of filling employed, higher than those for the initial copolymer (27.2 MPa) and those of the nanocomposites obtained from melt (Fig. 1). Tensile strength of the nanocomposite materials increased by 24 to $43 \%$ compared to the initial copolymer depending on the filling degree. The nanomaterials obtained by mixing from melt showed elongation at break, $\varepsilon 950-1220 \%$ (increase by 20 to $54 \%$ compared to VDF-HFP copolymer), at the content of $0.5-1.0$ mass $\%$ Cloisite ${ }^{\circledR} 15 \mathrm{~A}$ (Fig. 2). The highest Young modulus (150 - $190 \mathrm{MPa})$ had the composite materials obtained by the co-precipitation method and containing $0.5-1.5$ mass $\%$ filler Cloisite ${ }^{\circledR} 15 \mathrm{~A}$. 
Table 1. DSC-parameters of initial VDF-HFP copolymer and nanocomposite materials prepared on its basis by melt mixing and co-precipitation methods.

\begin{tabular}{cccccccccc}
\hline & \multicolumn{10}{c}{ Methods } \\
\cline { 2 - 11 } Content of Cloisite ${ }^{\circledR}$ 15A, mass $\%$ & \multicolumn{1}{c}{ Melt mixing } & \multicolumn{5}{c}{ Co-precipitation } \\
\cline { 2 - 11 } & $T_{m}^{I}$ & $T_{m}^{I I}$ & $T_{c}$ & $\alpha$ & $T_{m}^{I}$ & $T_{m}^{I I}$ & $T_{c}$ & $\alpha$ \\
& $\left({ }^{\circ} \mathrm{C}\right)$ & $\left({ }^{\circ} \mathrm{C}\right)$ & $\left({ }^{\circ} \mathrm{C}\right)$ & $(\%)$ & $\left({ }^{\circ} \mathrm{C}\right)$ & $\left({ }^{\circ} \mathrm{C}\right)$ & $\left({ }^{\circ} \mathrm{C}\right)$ & $(\%)$ \\
\hline \hline 0 & 132.4 & 131.9 & 95.5 & 23.9 & 129.8 & 129.7 & 95.1 & 28.7 \\
0.5 & - & - & - & - & 131.6 & 130.0 & 96.4 & 28.5 \\
0.75 & 133.8 & 133.7 & 97.6 & 22.4 & 132.6 & 130.5 & 96.9 & 28.3 \\
1.0 & - & - & - & - & 133.5 & 130.7 & 97.0 & 27.8 \\
1.5 & 135.8 & 136.6 & 100.8 & 21.6 & 134.0 & 130.8 & 97.3 & 27.2 \\
3.0 & 136.4 & 139.1 & 100.6 & 22.4 & 134.4 & 132.0 & 97.7 & 26.4 \\
6.0 & 140.6 & 142.2 & 106.7 & 20.7 & 135.6 & 133.2 & 98.4 & 23.4 \\
\hline
\end{tabular}

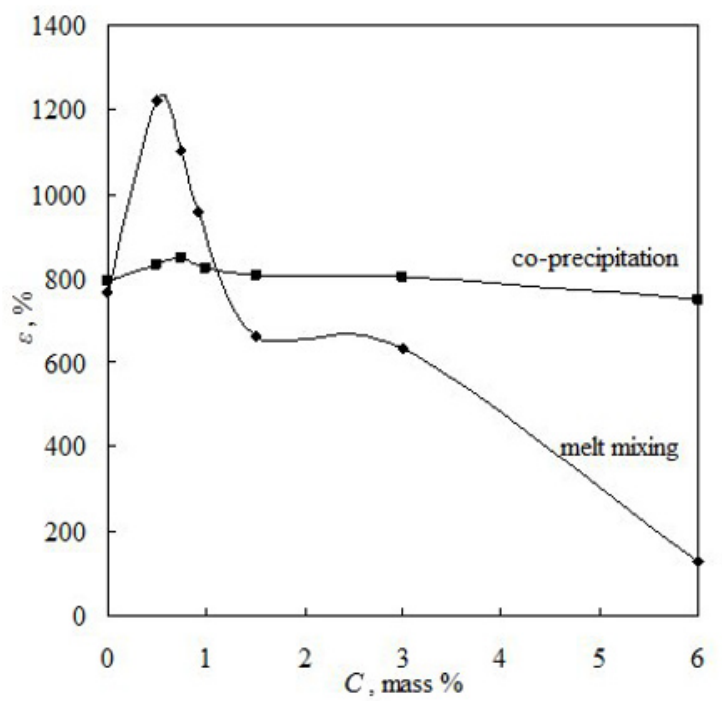

Fig. 2. Dependence of the elongation at break of the nanocomposite materials based on VDF-HFP copolymer on filler content.

Table 1 shows the temperatures of first $T_{m}^{I}$ and second $T_{m}^{I I}$ melting and crystallization $T_{c}$ of the nanocomposites obtained by both methods. The nanocomposites obtained by mixing from melt showed slightly higher temperatures of melting at first and second melting $\left(132.4-140.6{ }^{\circ} \mathrm{C}\right.$ and $\left.131.9-142.2^{\circ} \mathrm{C}\right)$ compared to these obtained from solution $\left(129.8-136.5^{\circ} \mathrm{C}\right.$ and $\left.129.7-133.2^{\circ} \mathrm{C}\right)$. As can be seen from Table 1, the degree of crystallinity, $\alpha$ of the composites obtained by mixing from solution was higher by $3-6 \%$ at the degree of filling $1.5-6$ mass $\%$ content of Cloisite ${ }^{\circledR} 15 \mathrm{~A}$.

The results obtained from the qualitative and quantitative determination of the content of $\beta$ phase were confirmed also by the XRD analysis. The X-ray diffractograms were analyzed with respect to the standard X-ray diffractograms of PVDF [13], since the small quantity of HFP in the VDF-HFP copolymer (15 mol \%) has not changed significantly the symmetry of the crystal lattice compared to that of the homopolymer PVDF [14]. The peaks at $2 \theta=17.7$ [15, 16], 18.4 [15-18], $19.9[15,16]$ and $26.6^{\circ}[15,16,19]$ correspond to 100, 020, 110 and 021 diffractions of the PVDF $\alpha$-phase while the peaks at $2 \theta=20.2,20.6$ [18], $20.7[15,19]$ and $20.8^{\circ}[15-17,19,20]-$ up to 110 and $200 \beta$-phase diffractions. The change in the diffractograms and the appearance of the basic peak above $20^{\circ}$ together with a smaller one at $2 \theta=18-19^{\circ}$ directly proves the formation of pure and prevalently oriented $\beta$-phase (Fig. 3a). For nanocomposites obtained by mixing from melt at Cloisite ${ }^{\circledR} 15 \mathrm{~A}$ content higher than 3.0 mass \%, the X-ray pattern transforms into a single-peak (Fig. 3b). The predominant crystalline phase in the initial copolymer is the non-polar $\alpha$-phase.

The XRD analysis of VDF-HFP copolymer and its nanocomposites obtained by different methods was supplemented by Fourier transform infrared spectroscopy (FT-IR). Fig. 4 illustrates the differences in the absorption bands of the initial 


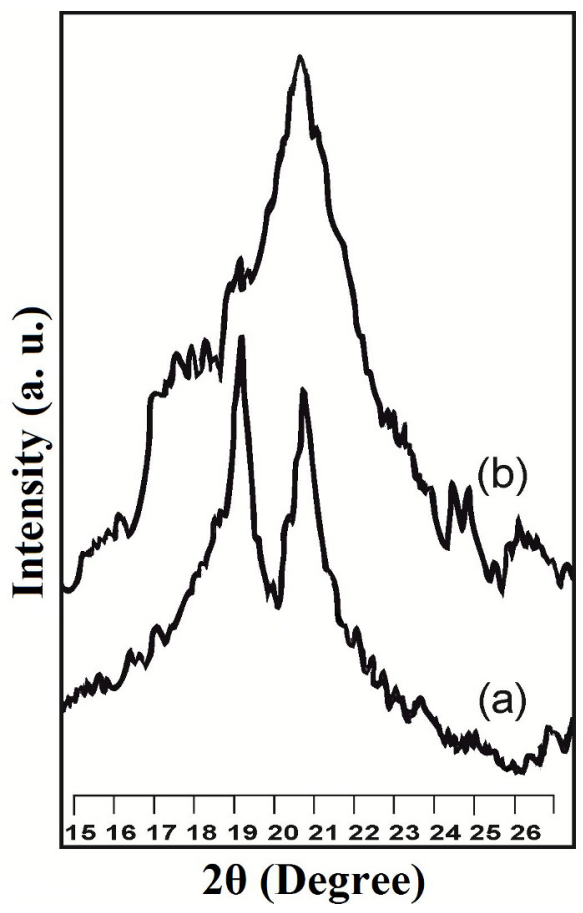

Fig. 3. X-ray diffraction patterns of the nanocomposite materials based on VDF-HFP copolymer at 0.75 (a) and 6.0 (b) mass \% filler content.

copolymer and its corresponding nanocomposites obtained by both methods. For all the samples studied, the peaks at 490,614 and $763 \mathrm{~cm}^{-1}$ characteristic of the $\alpha$-phase regularly decreased with the increase of filler content, at the expense of the increase of the main peak characteristic of the $\beta$ phase at $840 \mathrm{~cm}^{-1}$ (Fig. 4).

The values calculated for $F_{\beta}^{I R}$ by the FT-IR method for VDF-HFP copolymer and its nanocomposites prepared by melt mixing show that the increase of nanoclay content gave increased $\beta$-phase content from about $30 \%$ in the initial VDF-HFP copolymer up to $86 \%$ in the materials containing 3.0 mass $\%$ Cloisite ${ }^{\circledR} 15 \mathrm{~A}-$ Table 2 .

The initial VDF-HFP copolymer obtained by co-precipitation method contains mainly $\alpha$-phase. Similarly, with the addition of Cloisite ${ }^{\circledR} 15 \mathrm{~A}$ to the copolymer, $\alpha$-phase has fully transformed into $\beta$-phase. Thus, for the nanomaterials modified with 6.0 mass \% nanoclay, the amount of calculated $\beta$ phase was higher than $95 \%$ while at Cloisite ${ }^{\circledR} 15 \mathrm{~A}$ content less than 6.0 mass $\%, \beta$-phase was in the

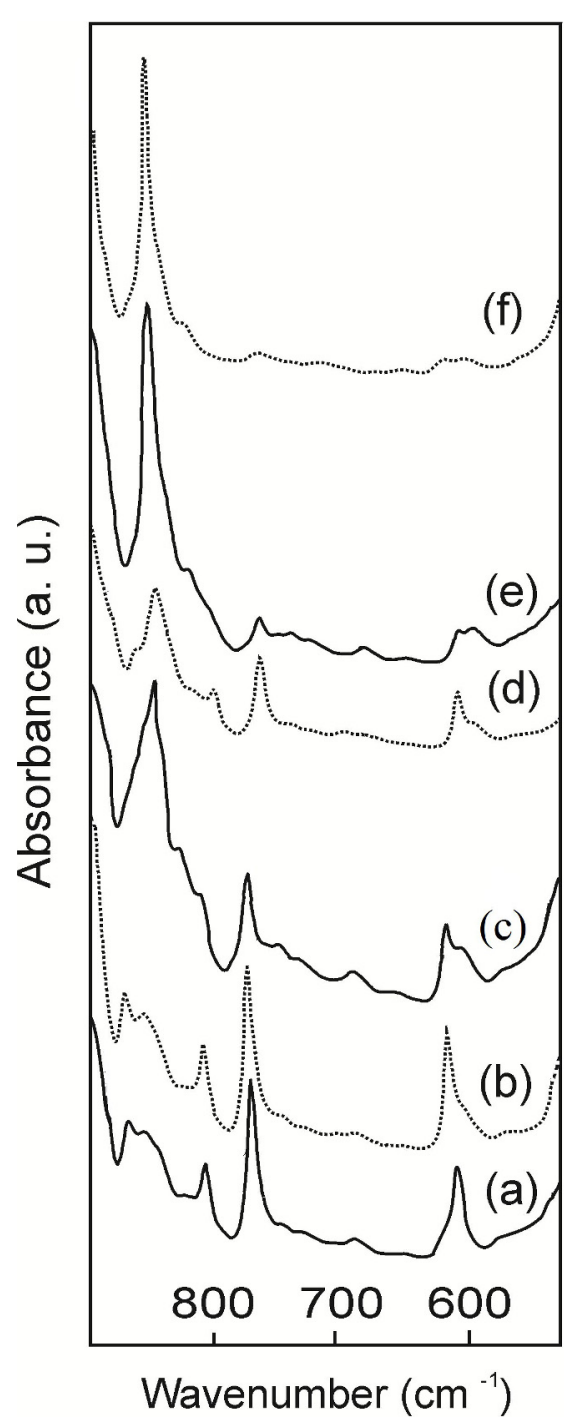

Fig. 4. IR-spectra of initial VDF-HFP copolymer (a and b) and nanocomposite materials on its basis at 0.75 (c and d) and 6.0 (e and f) mass \% filler content prepared by melt mixing (solid line) and co-precipitation methods (dotted line).

range of $47-82 \%$. The formation of $\beta$-phase in the studied compositions (Table 2) is also beneficial to the improvement of mechanical properties of the nanocomposites based on VDF-HFP copolymer.

\section{Conclusions}

Nanocomposites with enhanced tensile properties $(\sigma=37-38 \mathrm{MPa}$ and $\varepsilon=850-1220 \%)$ 
Table 2. Content of $\beta$-phase in the crystalline phase of initial VDF-HFP copolymer and nanocomposites prepared on its basis, at different contents of Cloisite ${ }^{\circledR} 15 \mathrm{~A}$, by melt mixing and coprecipitation methods.

\begin{tabular}{ccc}
\hline \multirow{2}{*}{$\begin{array}{c}\text { Content of } \\
\text { Cloisite }\end{array}{ }^{\circledR} 15 \mathrm{~A}$, mass $\%$} & \multicolumn{2}{c}{ Methods } \\
\cline { 2 - 3 } & Melt mixing Co-precipitation \\
\hline \hline 0 & 30 & 26 \\
0.5 & 54 & 47 \\
0.75 & 60 & 54 \\
1.0 & 63 & 54 \\
1.5 & 77 & 57 \\
3.0 & 86 & 82 \\
6.0 & 88 & 95 \\
\hline
\end{tabular}

were obtained on the basis of vinylidene fluoridehexafluoropropylene copolymer and organically modified montmorillonite Cloisite ${ }^{\circledR} 15 \mathrm{~A}$ by coprecipitation method and mixing from melt. The highest content of the piezoelectric $\beta$-phase in the material was $88-95 \%$ at 6.0 mass \% filler content. The nanomaterials were characterized also by X-ray diffraction analysis, differential scanning calorimeter measurements and Fourier transform infrared spectroscopy.

\section{References}

[1] Ma J., Xu J., Ren J.H., Yu Z.Z., MaI Y.W., Polymer, 44 (2003), 4619.

[2] Ray S.S., Oкамото M., Prog. Polym. Sci., 28 (2003), 1539.

[3] Dillon D.R., Tenneti K.K., Li C.Y., Ko F.K., SiCs I., Hsiao B.S., Polymer, 47 (2006), 1678.

[4] Giannelis E.P., Krishnamoorti J.R., Manias E., Adv Polym Sci, 138 (1999), 107.
[5] Humphrey J.S., Amin-SAnAYEI R., Vinylidene fluoride folymers, in: Encyclopedia of polymer science and technology, Wiley, New York, 2006, p. 510.

[6] Lovinger A.J., Poly(vinylidene fluoride), in: BASSETT D.C. (Ed.), Developments in crystalline polymers, Applied Science Publishers Ltd, Englewood, New Jersey, 1982, p. 195.

[7] PriYa L., Jog J.P., J. Polym. Sci. Pol. Phys., 40 (2002), 1682.

[8] Shah D., Maiti P., Gunn E., Schmidt D., Jiang D., Batt C., Giannelis E., Adv. Mater., 16 (2004), 1173 .

[9] Sobhani H., Razavi-Nouri M., Yousefi A.A., $J$. Appl. Polym. Sci., 104 (2007), 89.

[10] Huan Y., LiU Y., Yang Y., Wu Y., J. Appl. Polym. Sci., 104 (2007), 858.

[11] Salimi A., Yousefi A.A., Polym. Test., 22 (2003), 699.

[12] Rudhziah S., Muda N., Ibrahim S., Rahman A.A., Mohamed N.S., Sains Malays., 40 (2011), 707.

[13] GregoriO R., J. Appl. Polym. Sci., 100 (2006), 3272.

[14] Guan F., Pan J., Wang J., Wang Q., ZhU L., Macromolecules, 43 (2009), 384.

[15] Satapathy S., GUPta P.K., PaWAR S., VArma K.B.R., 2008, arXiv:0808.0419 [cond-mat.mtrl-sci].

[16] Tomer V., Manias E., Randall C.A., J. Appl. Phys., 110 (2011), 044107-1.

[17] Abbernt S., Plestil J., Hlavata D., Lindgren J., Tegenfeldt J., Wendsjo A., Polymer, 42 (2001), 1407.

[18] Song Y.M., Zhao Z.D., Yu W.X., Li B., Chen X.F., Sci. China Ser. B, 50 (2007), 790.

[19] Yamada E., Nishioka A., Suzuki H., Murasawa G., Miyata K., Koda T., Ikeda S., Polym. J., 41 (2009), 383.

[20] Yu L., Cebe P., J. Polym. Sci. Pol. Phys., 47 (2009), 2520 .
Received 2014-02-02

Accepted 2014-03-10 